\title{
The probability of sale and price premiums in withdrawn auctioned properties
}

Article

Accepted Version

Stevenson, S. and Young, J. (2015) The probability of sale and price premiums in withdrawn auctioned properties. Urban Studies, 52 (2). pp. 279-297. ISSN 1360-063X doi: https://doi.org/10.1177/0042098014529341 Available at https://centaur.reading.ac.uk/40903/

It is advisable to refer to the publisher's version if you intend to cite from the work. See Guidance on citing.

Published version at: http://usj.sagepub.com/content/52/2/279.abstract

To link to this article DOI: http://dx.doi.org/10.1177/0042098014529341

Publisher: Sage

All outputs in CentAUR are protected by Intellectual Property Rights law, including copyright law. Copyright and IPR is retained by the creators or other copyright holders. Terms and conditions for use of this material are defined in the End User Agreement.

\section{www.reading.ac.uk/centaur}

\section{CentAUR}

Central Archive at the University of Reading

Reading's research outputs online 
The Probability of Sale and Price Premiums in Withdrawn Auctioned Properties

\author{
Accepted for publication in Urban Studies
}

Simon Stevenson (University of Reading) \& James

Young (University of Auckland) 


\title{
The Probability of Sale and Price Premiums in Withdrawn Auctioned Properties
}

\author{
Simon Stevenson, University of Reading* \\ James Young, University of Auckland ${ }^{\dagger}$
}

\begin{abstract}
This paper examines the impact of the auction process of residential properties that whilst unsuccessful at auction sold subsequently. The empirical analysis considers both the probability of sale and the premium of the subsequent sale price over the guide price, reserve and opening bid. The findings highlight that the final achieved sale price is influenced by key price variables revealed both prior to and during the auction itself. Factors such as auction participation, the number of individual bidders and the number of bids are significant in a number of the alternative specifications.
\end{abstract}

\footnotetext{
* Corresponding Author: Henley Business School, University of Reading, Whiteknights, Reading, RG6 6UD, UK. Tel: +44-118-378-4008, e-mail: s.a.stevenson@ reading.ac.uk, ${ }^{\dagger}$ Department of Property, University of Auckland Business School, e-mail: james.young@auckland.ac.nz
} 


\section{The Probability of Sale and Price Premiums in Withdrawn Auctioned Properties}

\section{1: Introduction}

The last three decades have seen a large number of papers to have considered the theoretical constructs of auctions. This literature has considered a wide range of issues such as alternative auction methods; the preference of auction versus negotiated sales in terms of expected revenue; risk aversion from the perspective of both sellers and bidders; the probability of sale; the impact of the number of bidders; the nature of the information in particular the issue of common and private information and the importance of reserve prices. However, relatively few papers have empirically considered the impact of the auction process on the subsequent sale of assets that did not meet the reserve price, i.e. properties that were withdrawn at auction and sold subsequent to the event. In a residential property context, two key exceptions are Ashenfelter \& Genesove (1992) and Ong (2006). Ashenfelter \& Genesove (1992) found evidence that successful auction sales achieved an average premium of $13 \%$ over those properties initially offered at auction, withdrawn, and then subsequently sold. Ong (2006) extends this analysis to find that issues such as the attendance at the auction and whether no bids were submitted at auction have a positive and negative impact respectively on the probability of sale.

However, these papers, as with many in the broad auction literature have been constrained by the availability of data, indeed it remains one of the most common challenges in the field. This paper considers the residential auction market in Dublin, Ireland and specifically examines the dynamics of properties unsuccessfully offered for sale through auction. The dataset utilised in the paper includes information often missing from empirical auction research, including; the undisclosed reserve, attendance at the auction and the number of bids and bidders. A key advantage through the use of this data is that we do not have to rely on proxies to capture the impact of different factors. A further consideration in the examination of the Irish market is that auctions were an extremely popular form of sale mechanism during the boom period. The sample period covered in this paper is 1998 through 2002 and so allows an examination of a distinct period when auctions were frequently utilised, especially at the premium end of the market. The remainder of the paper is set out as 
follows. The next section briefly outlines the process for auction sales in the Republic of Ireland. Section 3 considers the existing empirical work examining housing auctions while Section 4 provides information on the dataset and the methodological framework adopted. Section 5 presents the empirical results and concluding comments are made in the final section.

\section{2: Auction Process in Ireland}

Residential properties in Ireland that were sold through auction are done so using the first-price English open-outcry method. In determining the sale mechanism utilised, this decision was made by the vendor in association with the estate agent prior to the marketing of the property. This decision process is made easier in the Irish context because the agents involved with both sale forms are the same firms. The result is that if an auction sale method is decided upon, the agency concerned acts as the auctioneer for the sale. As Stevenson et al. (2010) illustrated, auctions tended to be used at the premium end of the market in Ireland, in common with markets like Australia (Lusht, 1996) and New Zealand (Doutzour et al., 1998). This finding is in contrast to markets such as the United States (DeBoer et al., 1992; Mayer, 1998 and McAfee at al. 2002) and Singapore (Ong et al., 2005, Ong 2006) where a large proportion of auctioned properties are distressed sales. This obviously leads to differences in terms of the motivation of the sellers concerned and is of particular importance in terms of the reserve estimates. As this sample consists of willing sellers, the reserve prices act as an estimate of market value for the property ${ }^{1}$. This is in sharp contrast to previous studies where the reserve price is often a measure of outstanding mortgage debt or unpaid taxes (DeBoer et al., 1992; McAfee et al., $2002)^{2}$.

Auction sales in Ireland generally follow a standard process. A three to four week marketing period will take place prior to the auction. This period is important to the auction as it will allow them to gauge potential demand for the property prior to the auction. As part of the marketing material a guide price will generally be provided. It is important to note that the guide price is neither a binding commitment on the part of the vendor or agent, nor is it the reserve price. The advertised guide price is rather a publicly available estimate of the property's value and is effectively a component of 
the marketing process. Stevenson et al. (2010) argue that guide prices for auction sales in Ireland are underpriced, hypothesizing that this may be due to auctioneers attempting to encourage bidders and participation in the auction. Their analysis, using a sample from the Dublin market, finds that whereas properties sold through auction did so at a significant premium to private treaty sales, the advertised guide prices for auctioned properties was significantly lower than for private treaty sales.

The reserve price for an auctioned property will be agreed on the day of the auction by the vendor in association with the auctioneer. The marketing period will have helped the agent in gauging potential demand and aided in the advice they provide to vendors with respect to an appropriate reserve. The reserve set before the auction is the minimum acceptable price which the vendor will consider. The reserve is not made public either prior to the auction or necessarily during the auction itself. This is in contrast with property auctions in other countries, such as Australia, where the reserve is made public (Lusht, 1994, 1996). The only point during the auction process when the reserve may be revealed is during the auction where it is common for the auctioneer to declare that the property is 'on-the-market'. Whilst it is not a legal requirement, in the majority of cases in our sample the auctioneer did so at some point after bidding had exceeded the reserve price. As is the case in most English openoutcry auctions, as the reserve is the minimum acceptable price which the vendor will consider, if it is not achieved the vendor has the option of withdrawing the property from the market. It is these properties that this paper pays particular attention to. The custom in Ireland is that the right of first negotiation lies with the highest unsuccessful bidder. As will be noted shortly, the majority of properties withdrawn do sell very quickly after the auction.

A major distinction between private treaty and auction sales in Ireland is the role of the initial deposit and the closing process. Whilst transaction costs, commissions and other agency fees are identical in the case of private treaty and auction sales in Ireland, for private treaty sales the initial deposit is refundable up until the point that initial contracts are signed, a period generally 4 to 6 weeks following the initial agreement on price. In the case of auctions, sales contracts are signed on the day of the auction and the successful bidder will be required to sign initial contracts and place a $10 \%$ non-refundable deposit before the close of business on the auction day. 
Furthermore, the successful bidder at auction is required to close the property sale within 6 weeks of the date of the auction. This not only means that there is an immediate financial cost for successful bidders, but also it is imperative that serious bidders have financing arrangements and any property inspections completed prior to the auction due to the non-refundable nature of the $10 \%$ deposit $^{3}$.

\section{3: Auction Literature and Housing Assets}

Whilst there is a relatively large number of papers to have considered auctions in a real estate context the majority have concentrated their focus upon the broad issue of whether auctions or private treaty negotiations are the preferred sales mechanism. In part due to the difficulty in obtaining sufficiently in-depth data, empirical work on other issues has been relatively limited. With respect to those papers that have considered the broad sale mechanism issue, the evidence presented has been very mixed, particularly when considering results across different markets. The contrast in results obtained is of interest in the context of the broad auction literature. For example, papers such as Wilson (1977) and Milgrom (1989) argue that for goods that are of high quality, are not standardized and where the market clearing price is unstable, then auctions will be preferred over negotiated sales. Furthermore, when goods are heterogeneous then prices will also display greater uncertainty (Milgrom, 1989 and Bulow \& Klemperer, 1996). In the case of English auctions with no reserve prices, Bulow \& Klemperer (1996) show that a simple competitive auction with one additional bidder will result in higher revenue in comparison to an optimally structured negotiated sale that has one less bidder. They thus argue that the benefit of having additional bidders is greater than the value of negotiating skill. Even in the case where the cost of auctioning an asset may be high, auctions may be the preferred route. Wang (1993) argues that if the marginal revenue curve associated with the valuation the bidder attaches to the asset is sufficiently steep then auctions will be the optimal sale mechanism ${ }^{4}$.

Despite this evidence, a large proportion of the empirical literature to have examined housing markets has provided evidence that properties sold through auction sell at a discount in comparison to private treaty sales. This is certainly true from the majority of studies to have considered the United Sates (e.g. Mayer, 1995, 1998; Allen \& 
Swisher, 2000). Mayer (1995) argues that as vendors selling privately are not time constrained they can wait longer in order to find a buyer more matched in terms of price. This is a similar argument to that presented in Adams et al. (1992) albeit in the context of slow Dutch auctions, and one that Mayer (1995) refers to as the Cost of Liquidity. In the context of auctions, there is a greater risk of mismatch, hence auction participants do not bid up the price. Furthermore, Mayer (1995) argues that properties that display less heterogeneity have a lower Cost of Mismatch and should therefore sell for a lower discount. Likewise, for more heterogeneous properties, they will be higher mismatch costs. Ong et al (2005) in their empirical examination of auctions in Singapore provide results that support the theoretical constructs of Mayer (1995). They find that apartments and condominiums, which can be viewed as being more homogeneous in nature than detached or semi-detached houses, have a higher probability of sale.

Outside of the United States, however, there is evidence to suggest that an auction premium should exist in the context of property auctions. Studies such as Newell et al. (1993) and Lusht (1996) for Australia, Dotzour et al. (1998) in the case of New Zealand, and Stevenson et al. (2010) for Ireland have all found evidence indicating the presence of an auction premium. Stevenson et al. (2010) is of particular relevance given that it considers sales for the same market as the current paper, Dublin, and over a similar time-period, 1997 to 2004. Based on a sample of 2,657 sales, a significantly positive coefficient $(0.3157)$ is reported with respect to auction sales. Whilst it would initially appear that these results contradict Mayer (1995) this is not necessarily so. Mayer (1995) acknowledges that his model assumes that a seller cannot adjust the price in the face of two bidders willing to pay the guide price. Therefore, in booming market where this may more commonly occur, auctions may provide an opportunity to maximize revenue as bidders can raise prices in excess of the guide price. Additionally, the auction discount would be reduced in circumstances where a greater number of bidders attended. This combination of market conditions and increased participation is a key element in reducing the cost of mismatch in property auctions.

Mayer (1998) provides empirical evidence on role of market conditions relating to property auctions, with discounts ranging from $9 \%$ to $21 \%$ in the Dallas housing market crash of the late 1980 's to lower discounts $(0 \%$ to $9 \%)$ found in the booming 
Los Angeles market of the mid-1980s. It is important to note that whilst discounts were still observed in these cases, they were of a lower magnitude during boom conditions. In contrast, most of the studies that have reported auction premiums are from market samples dominated by rising or stable property markets. Certainly in an Irish context, the use of auctions has largely ceased in recent years following the collapse of the housing market in 2007. Mayer (1998) further argues that issues such as the media attention that surrounds the use of auctions may also influence these findings and encourage a short-term non-sustainable auction premium. Again, there is some supporting evidence for this position with regard to those studies providing evidence of an auction premium. Stevenson et al. (2010) report that in their tests for selectivity bias the time dummies are increasingly negative, lending support to the argument that a fall in popularity of auctions as a sale method later in the sample was due partly to relatively weak market conditions in 2001, a fall in the sales rate at auction, and growing adverse media attention concerning the high premiums over guide prices that auctions were achieving.

With respect to the number of bidders, non-property papers such Saidi \& Marsden (1992) and Chen et al. (2003), together with those to have directly considered real estate such Ching \& Fu (2003), Ong et al. (2005), Ong (2006) and Ooi et al. (2006) have all provided evidence that the number of bidders significantly impacts, in a positive sense, upon either the price obtained or the probability of a sale being achieved $^{5}$. Although in a different context, Gilbert \& Klemperer (2000) illustrate that it may be more profitable for a seller to ration output, thus selling at a fixed price at a level at which demand exceeds supply, rather than selling at a higher price that clears the market. The underlying rationale here relates to the idea that the offering of lower price acts as an incentive for more buyers to enter the market. In the context of our paper this does have a direct relevance; furthermore, it can be tied to the arguments of Glower et al. (1998) who note that vendors convey information about their desire to sell the property through the listing price that is set. The role of bidders can in some respects also be tied to the issue of market conditions, as it is likely that auctions undertaken during stronger conditions will see a higher number of potential bidders. Goeree \& Offerman $(2002,2003)$ explicitly argue that efficiency and therefore the revenue generated, will be higher when more bidders enter the auction ${ }^{6}$. Mayer (1995) argues that a rise in the number of bidders also increases the likelihood of the 
participation of high-value bidders. In an auction context, this could be viewed as those with higher private values of the property concerned. The recent work of Chow et al. (2011) also notes this. They argue that auctions will be the preferred sale mechanism in a case where bidders with higher valuations participate ${ }^{7}$.

The number of bidders is also related to the concept of bid-shading. Bid-shading is more commonly associated with common-value auctions with incomplete information where due to the risk of a winner's curse bidders may bid below their valuation. However, bid-shading can also be considered in the context of English Auctions. In this context bid-shading may occur in an attempt to optimize their expected value. This is rationale as if an auction participant automatically bids at a level equal to their valuation then they gain nothing if they are successful in the auction. By reducing the bid they would increase their expected value, albeit at a reduce probability of being the successful bidder. It would however be expected that in the presence of an increased number of bidders the degree of bid-shading observed would be reduced, especially where private values play an important role, leading to a higher final sale price $^{8}$.

However, whilst market conditions can play a role in the success or otherwise of auctions, the differences observed across countries can be due to an additional factor, namely the type of properties sold through auction. In Ireland, as in countries such as Australia and New Zealand, houses sold through auction generally tend to be those at the premium end of the market. In an Irish context this is illustrated in Stevenson et al. (2010) with $43.66 \%$ of auctions being in the highest decile alone. Furthermore, Stevenson et al. (2010) note that a significant auction premium was only noted in properties selling in excess of $€ 500,000$. Papers such as Wilson (1977) and Milgrom (1986) provide a theoretical context for such results, arguing that auctions will be preferred in the case of high quality goods and those that are less standardized. Higher value properties would be a typical case of such a class of assets. Property value and sale mechanism choice can be related to the issue of scarcity. French \& McCormick (1984) argue that a vendor will opt for a negotiated sale when they can either identity the highest potential bidder in advance or when they is reduced dispersion in the value, i.e. greater homogeneity. In contrast, where greater heterogeneity is observed then auctions may be preferred. In relatively cheaper property submarkets there will 
be increased market activity in terms of the number of possible properties on the market, therefore a greater availability of comparable sales information. This has two implications. Firstly, that there should be a higher level of certainty regarding the true value of the property. Secondly, the increased supply of close substitutes means that bidders have greater choice. In contrast, higher value and more heterogeneous properties effectively contain a higher degree of private value relating to the specific characteristics of the property. Effectively, a scarcity issue comes into play ${ }^{9}$. This could lead to more determined bidding and thus the greater efficiency of auctions. A further factor that may also play a role at the higher end of the market relates to financing constraints. It may be the case that bidders at the lower end of the market are subject to greater constraints in this regard and therefore an auction premium is not observed ${ }^{10}$.

The influence of market conditions may also have an impact in another respect. This is concerned with the nature of the bids themselves and the information revealed during the auction process. This is important in the context of our analysis of withdrawn properties. Although the auction sale was not successful, information concerning bidding and value may be revealed during the auction process. Lusht (1996) notes the importance of the auction process when bids are not independent but rather affiliated. Lusht (1996) argues that the actual auction process reveals additional information that would be otherwise unobserved in the case of pure independent bids. It has the effect that a bidder's private value is influenced by the information revealed at the auction in terms of the behaviour of other bidders. It may therefore lead to a bidder upwardly revising their valuation. The combination of this use of other bidder's revealed valuations together with the price rule also ensures that there is a preference in terms of revenue over sealed bid auctions (Levin et al., 1996). Milgrom \& Weber (1982) argue that English open outcry auctions will be revenue maximizing if bids are affiliated rather than independent in comparison to sealed bids as a high valuation assigned by one bidder makes higher valuations by other bidders more likely $^{11}$.

Goeree \& Offerman $(2002,2003)$ note that the combination of common and private values can lead to inefficiencies. One of the examples that they note is when a party with a lower private value then another bidder may still end up purchasing the 
asset/good where they have placed a higher valuation on the common valuation. Whether this higher assessment of the common value is realistic or not is irrelevant. They argue that auction efficiency will increase, and therefore the vendor's revenue, with increased certainty concerning common values. The argument is based upon the premise that uncertainty regarding the common value can, in the limit, override bidder's private information. At the opposite end of the spectrum, if there was no uncertainty regarding the common value, then the auction reduces to a pure private value auction $^{12}$. In a broader context Goeree \& Offerman $(2002,2003)$ highlight that in practice few auctions can be neatly categorized as displaying solely private or common values. In the context of residential property it is clearly the case that bidders will take into account both common information (e.g. potential price appreciation) and private information (e.g. location and architectural preferences).

As noted above, most of the auction literature in this area has been concerned with different sale mechanisms and specifically that English open outcry auctions are optimal when bids are affiliated. However, in the context of our study there is an additional element. Even if a property is withdrawn from sale at auction the bids can still be affiliated. This is especially so if the final purchaser was present at the auction and therefore observed the behaviour of other bidders. As we discuss in the following section, the time on market from the auction to subsequent sale is very short in most cases. This would imply that the purchaser was present at the auction and possibly the highest unsuccessful bidder given the convention to give them the first right of negotiation. This also adds in the transmission of information from the auction to the subsequent private treaty negotiations.

\section{4: Data}

The data analysed consists of residential properties located in the Greater Dublin metropolitan area that were put forward for sale through at auction during the period 1998 to 2002. The data was provided by one of the major auctioneer/estate agents in Dublin and consists of all information relating to the property and auction contained in their records ${ }^{13}$. It is important to highlight market conditions during the sample period. The 1998 through 2002 period was characterized by strong housing market conditions and rapid price appreciation. As noted previously, studies such as Mayer 
(1995) have illustrated the importance of controlling for market conditions. However, in the context of the current study, whilst time dummies are included in the model specifications, there is less need to control for varying conditions. However, the results obtained do need to be considered solely in the context of strong market conditions and may not necessarily transfer to weaker markets. In addition, the broader comments of Mayer (1995) with respect to the optimality of auctions versus negotiated sales in booming markets needs to be taken into consideration ${ }^{14}$.

In total data on 404 properties is available. The sample includes properties that were both successfully sold at auction and those properties that were withdrawn. The withdrawn sample effectively includes three types. The first is those properties initially marketed as being offered at auction but that were sold privately prior to the auction. The second sub-sample consists of those properties that were withdrawn at auction and subsequently sold through private treaty negotiations. The final set contains properties that did not successfully sell after being withdrawn at auction. It should be noted that none of the withdrawn properties were re-auctioned; rather all of them were subsequently offered for sale through private treaty. Out of the total sample of 404 properties, 198 were successfully sold at auction, 15 were sold prior to the auction, and the remaining 191 were withdrawn at auction. Among the 191 withdrawn properties, 77 of them subsequently sold by private treaty ${ }^{15}$.

There is potential selectivity bias present in all studies of sale mechanisms in that the vendor's decision as to the mechanism selected may be associated with missing price affecting variables. This may result in differences in prices being wrongly attributed to the sale mechanism adopted rather than the omitted variable. Given that we are solely considering properties at least initially advertised as being sold through auction we avoid this issue directly. Stevenson et al. (2010) do consider selectivity in the context of the Irish market and in their sample of privately sold and auctioned properties do not find evidence of selectivity bias.

The variables concerning the auction consist of the guide price, the undisclosed reserve price where available and the sale price where appropriate. In cases where the property was withdrawn and re-advertised for private treaty sale, the revised guide price for the property is also noted where available. As the auction house continued to 
act as the estate agent for the property any change was held on their records. Undisclosed reserve prices are available for 240 of the 404 properties in the sample. In the remaining cases, the reserve was not available due to the property being sold prior to auction, and therefore a reserve was not set, or because the information was not recorded in the auction book. Data is also available on the number of bids, number of bidders on a particular property, the attendance at the auction, and whether multiple auctions were held that day. This data was recorded on the day of the auction by the agency and then subsequently released to ourselves. Throughout the auction a member of staff would note all bids, identifying individual bidders. This then allows a separation of the number of bids from the number of bidders. Attendance is defined by a head count of people in the room. This is aided by the auctions taken place in the offices of the agency, not at the property as is sometimes the case, for example in markets such as Australia. The multiple auction dummy is based on the records from the firm and was simply based on whether more than one auction took place on one day. This is of interest as the firm would hold the auctions together, back to back, rather than at different times in the day ${ }^{16}$.

In addition to the data directly related to the auction process, information is also available for a variety of property specific variables. These include the location of the property, the type of property, the date of sale, the availability of parking facilities, the number of bedrooms, and the number of bathrooms. Unfortunately reliable floor area data was not available, leading to the bedroom and bathroom data having to act as proxies for property size.

Table 1 provides summary statistics for the sample, both in total (Panel A) and for the withdrawn sub-sample (Panel B). Panel C reports the split across both samples by location and property type. The dummy variables used with respect to location divide the properties into the following areas of Greater Dublin: Central City, South City, North City, South County and the Periphery of Dublin. Dublin postcodes have even numbers in the south of the city and odd numbers in the north which makes a clear demarcation of the sample straightforward. The Central City is defined by the postcodes D1, D2, D7 and D8. The South City includes all remaining even postcodes and the North City all remaining odd numbered postcodes. South County Dublin contains all areas within the County of Dublin south of the River Liffey, but not 
formally within the City of Dublin. The remaining areas of the greater metropolitan area, including the remaining sections of County Dublin as well as parts of Kildare, Louth, Meath and Wicklow are grouped together. The location of properties in the sample is dominated by two key submarkets, namely South City and South County Dublin, which represent the most highly priced submarkets in Greater Dublin, thus confirming that auctions were used primarily at the premium end of the market during the period covered in this sample. Out of 404 properties in the overall sample, 161 properties were located in the South City and a further 133 were located in South County Dublin. The sample is fairly evenly spread by property type, with the following categories used; detached (110), semi-detached house (96), bungalow (69), terrace/mews (104) and apartment (25). Compared to previous studies of the Irish auction market these are relatively consistent breakdowns ${ }^{17}$. Whilst small individual samples are observed for some locational or sector segments (e.g. apartments and the city centre) given the modelling framework adopted and the fact that they are not considered in isolation reduces the risk of bias in this respect. However, the overall sample size and the concentration of it in South Dublin and in detached and semidetached houses, needs to be considered when examining the empirical findings.

When one considers solely those properties that did not sell and were withdrawn they are not any substantive differences in either the property type or location segments. With respect to the property types the only shift worth commenting upon is that there marginally fewer semi-detached properties were withdrawn and marginally more detached properties. However, the figures do not, even in these cases, shift substantially. With respect to the data reported in Panel's A and B there are not noticeable differences across the two samples. One point that is worth noting is the short time on market for withdrawn properties post auction. The average time to subsequent sale is only 9.88 days, whilst the median is just one day. As noted previously in the paper, convention in the Irish market at this time held that the right of first negotiation was with the highest bidder. These figures would imply that in many cases the ultimate buyer was a participant at the auction, if not indeed the highest unsuccessful bidder. This does indeed add to the underlying rationale of the paper as it highlights the flow of information and how it was transmitted from the auction to the purchaser and its impact upon the subsequent sale price ${ }^{18}$. 


\section{5: Empirical Analysis}

The first section of the empirical analysis considers whether the final sale mechanism impacted upon the price achieved. The broad methodological framework adopted is similar to that adopted in many previous papers, such as Lusht (1996), Mayer (1998), Ong et al. (2005) and Stevenson et al. (2010). The model used is a standard log hedonic model as displayed in Equation (1).

$\ln (\text { sale price })_{i}=\alpha+\beta \mathbf{X}+\varepsilon_{i}$

$\mathbf{X}$ represents the hedonic characteristics of the property. Dummy variables are included to indicate whether the property was successfully sold at auction or whether it was sold prior with the missing dummy referring to withdrawn properties. However, given that the dependent variable is the sale price, the withdrawn properties included in this specification are those that did subsequently sell. In addition to the sale mechanism dummies the model also includes property specific variables concerning the number of bathrooms, number of bedrooms and whether parking facilities were available. Finally, groups of dummies relating to property type, location and year of sale are also include. The base property was a bungalow, located in North City Dublin that sold in $2000^{19}$.

The results in Table 2 report a positive coefficient for properties selling at auction; however, it is not statistically significant at conventional levels. The interpretation of this finding needs to be carefully considered, particularly in the context of the results in Stevenson et al. (2010) who found evidence of an auction premium. A key element that differentiates these two samples is that Stevenson et al. (2010) examined a sample containing both auction and private treaty sales. In contrast, the current sample is limited to only those properties that were at least initially put up for sale by auction. Therefore, when considering the sold at auction dummy it important to understand that this is relative to the sale price achieved by properties withdrawn and subsequently sold after going through the auction process. This is an issue that we will return to, in that it may be that although the withdrawn properties did not sell at auction, their final realised price was influenced by the auction process, hence the 
lack of a significant coefficient in this regard. This is consistent with the arguments presented in Lusht (1996) in terms of bidder's valuations being influenced by the information revealed by other bidders in an auction setting. The remaining coefficients are generally in line with expectations with significant positive coefficients reported with respect to the number of bedrooms and bathrooms, apartments, detached properties and those located in South City and South County Dublin. In terms of the year dummies, they reflect the strong upward movement in the market during the sample period with a significant negative coefficient for 1998 and positive findings for 2001 and 2002.

Table 2 also reports the findings when the log of the guide price is substituted in the place of the realized sale price. The results for the majority of the variables are as reported when sale prices were considered. It is however with respect to the auction dummy that an interesting finding is observed. The properties that were successfully sold at auction appear to have been advertised at a significantly lower guide than those that did not sell and were withdrawn. Again, the comparison with Stevenson et al. (2010) is not as simple as one may initial think as our sample is constrained to solely those properties that were advertised as being sold through auction. In this case it may be that the guide price plays a more subtle role. The result can be interpreted that properties whose relative guide price is lower are more likely to sell. Therefore, in that sense the results support the view of Stevenson et al. (2010) in that the guide is being used as a marketing tool in order to encourage participation in the auction and hence increase the likelihood of a successful sale.

The main empirical results are however directly concerned with the influence of the auction process on the prices achieved subsequently for properties that were withdrawn. Few papers have considered this, the two primary exceptions in a housing context being Ashenfelter and Genesove (1992) and Ong (2006). Our withdrawn sample includes a total of 191 properties. Of these 77 were subsequently sold, 114 remaining unsold. As with the overall sample, property specific characteristic data is available, as are the details from the auction itself. The analysis is based upon a probit model that considers the probability of sale. The dependent variable is a binary variable taking the value of unity if the property was sold post auction and zero otherwise. The independent variables include property specific variables, namely; the 
number of bathrooms, bedrooms and a dummy indicating whether the property had parking facilities. Groups of dummies were included to capture the impact of property type, location and the year of sale. The base property was a bungalow, located in North City Dublin, sold in 2000. The auction variables included relate to the attendance at the auction, the number of bidders, the number of bids and whether multiple auctions were held that day. We also include a variable which takes the value of unity if no bids were made at auction and zero otherwise $\mathrm{e}^{20}$.

The findings from the Binary Probit model are included in Table 3 and take three alternative specifications. In addition to the core property and auction variables these include, in turn, the New Guide-to-Old Guide premium, the New Guide-to-Reserve premium and the Reserve Price. None of the variables relating to attendance at auction and the number of bids/bidders are significant in this case. While this is in sharp contrast Ong (2006), that sample of Singaporean properties primarily consisted of apartments and contained a large number of distressed sales. The resulting more homogeneous sample may explain the difference in the findings reported. However, the No Bids dummy is significant in two of the models, and has the anticipated negative sign. Therefore, if no bids were achieved at auction it reduced the likelihood of a subsequent negotiated sale. The other coefficients that report significant results from the probit are those relating to the year dummies. The dummy for 1998 is significant in each specification, as are those for 1999 and 2001 in Model I. This is very likely due to the strong market conditions during this period.

The results also show that the Reserve Price has a significant negative impact in the third specification. This may be reflecting an over-valuation of the property that, despite the failure to sell at auction, continues into the subsequent private negotiations. However, this result needs to be viewed also in the context of the significant positive coefficient relating to the New Guide-to-Old Guide premium in the second model. This would imply that if the guide price was revised upwards following the auction, it significantly increased the probability of a subsequent sale. While this may appear counter intuitive, two issues arising from this finding. The first issue is that any upward movement in the guide following the auction may reflect an indication of demand for the property amongst potential buyers, even if this demand did not result in a successful sale. Secondly, it needs to be remembered that 
the initial guide price was originally set with an eye towards an auction sale with the aim of encouraging participation in the auction. Therefore, an increase in the guide price after withdrawal at auction may be a reflection of a more realistic assessment of the value of the property. This can be illustrated by looking at the average figures from the raw data where the withdrawn sample had an average initial guide price of $€ 487,584$ whilst the average revised, post auction, guide price increases to $€ 509,410$. Out of 190 observations, 86 properties see an upwards adjustment, only 4 see a reduction, and the remainder see no change. If you constrain the sample to only those properties where the reserve prices are available, the situation becomes clearer. With 88 properties in the sample where reserve prices are available and the properties were subsequently withdrawn, the average initial guide is $€ 423,864$, rising to $€ 453,205$ post auction. Again in the majority of cases the guide was adjusted upwards (52 cases) with only one example of a downward adjustment. However, the average reserve price of the 88 properties was $€ 478,807$. Therefore, while a property may have seen its guide increased, it was still on average less than the reserve. Indeed, the average percentage difference between the revised guide and the reserve is $-4.31 \%$. Hence, whilst the guide has been adjusted upwards this is perhaps reflective of an admission that the initial guide was not a true indication of the underlying value. The fact that on average the revised guide is less than the reserve shows the impact of a failure to sell and the use of a perhaps more realistic assessment for subsequent negotiations.

Table 4 presents the final set of empirical findings which relate the analysis of the sale premiums achieved in the case of the withdrawn properties. The dependent variable is the percentage premium of the achieved sale price relative to the opening bid, guide price and reserve respectively ${ }^{21}$. The primary issue of note in these results relates to the renewed importance of the auction process with respect to participation. The Number of Bidders is significant in two of the three specifications, whilst the Number of Bids is significant in one model each. Overall Auction Attendance however fails to achieve significance in any of the models. These findings highlight the importance of the auction process, in terms of encouraging interest and participation and are in line with the findings of Ong (2006). However, the findings do have to be considered with a degree of caution. It is important to remember that the opening bid and the guide price contain information that does not necessarily reflect an estimate of market value. Therefore, any discounting of these figures and therefore a higher premium does have 
to be viewed in that light. The result with respect to the Reserve Price is however more robust as it should more accurately reflect the agents and vendors assessment of market value. Therefore, any significant findings here can be viewed, at least with a greater degree of certainty, that the Number of Bids is significant in the price achieved post auction.

\section{6: Conclusion}

Existing empirical work that has considered auctions in a property context has largely concentrated on the issue of the choice of sale mechanism and whether properties sold at auction achieve a different price than those transacted privately. In contrast, few studies have considered the issue of whether the auction process impacts upon the sale price achieved by those properties that were initially withdrawn from sale at auction and subsequently sold through negotiation. In considering variables that are often missing from much of the empirical work on auctions, it was found that the reserve price, initial guide prices, and after auction guide prices provide additional price information to auction participants. The resultant impact on subsequent sale after withdrawal of a property from auction and for price premiums after withdrawal is associated with key price variables revealed both prior to and during the auction itself.

In part the empirical results reported may be due to, or enhanced, due to the practices present in the Irish market during this period. The convention that vendors negotiated initially with the highest unsuccessful bidder may explain a number of issues arising from our results. Firstly, it helps to explain the very short time to sale post auction figures reported. Secondly, even if the eventual purchaser was not the highest bidder but just present at the auction, it would aid in the flow of information. This helps to underline our core hypothesis that information revealed at the auction significantly impacts upon the final sale price achieved. This includes the transmission of indirect information concerning private values through variables such as attendance and the number of bids and bidders.

Whilst the results do illustrate the importance of the auction process in the determination of sale prices, even in the case of unsuccessful auctions, the needs to be a degree of caution voiced with respect to some issues. The results are specific not 
only to be an individual market but also one that was observing a period of sustained house price appreciation during this period. Whilst the auction market witnessed a virtual collapse following the reversal in market conditions in 2007, it would ideally have been nice to have data covering a broader range of market conditions. As frequently observed in the housing auction literature open outcry English auctions can have different dynamics at different stages of the market cycle. In addition, this is added to given the concentration of our sample in relatively heterogeneous high value properties. At the same time, it should be noted that the results are consistent with those reported in Ong (2006) who considered a far more homogenous sample, namely Singaporean apartments. 


\section{References}

Adams, P., Kruger, B. \& Wyatt, S. (1992). Integrating Auction and Search Markets: The Slow Dutch Auction, Journal of Real Estate Finance and Economics, 5, 239-254.

Allen, M.T. \& Swisher, J. (2000). An Analysis of the Price Formation Process at a HUD Auction, Journal of Real Estate Research, 20, 279-298.

Ashenfelter, O. \& Genesove, D. (1992). Testing for Price Anomalies in Real Estate Auctions, American Economic Review, 82, 501-505.

Berry, J., McGreal, S., Stevenson, S. \& Young, J. (2001). Government Intervention and its Impact on the Housing Market in Greater Dublin, Housing Studies, 16, 755-769.

Bulow, J. \& Klemperer, P. (1996). Auctions versus Negotiations, American Economic Review, 86, 180-194.

Campbell, C.M. \& Levin, D. (2006). When and Why Not to Auction, Economic Theory, 27, 583-596.

Chen, A., Liaw, G. \& Leung, M. (2003). Stock Auction Bidding Behavior and Information Asymmetries, Journal of Banking \& Finance, 27, 867-889.

Ching, S. \& Fu, Y. (2003). Contestability of Urban Land Market: An Event Study of Government Land Auctions in Hong Kong, Regional Science and Urban Economics, 33, 695720.

Chow, Y.L., Hafalir, I. \& Yavas, A. (2011). Auction versus Negotiated Sale: Evidence form Real Estate Sales, working paper, Department of Real Estate, National University of Singapore.

D'Agostino, A., McQuinn, K. \& O'Reilly (2008). Identifying and Forecasting House Price Dynamics in Ireland, Research Technical Paper 3/RT/08, Central Bank \& Financial Services Authority of Ireland.

DeBoer, L., Conrad, J. \& McNamara, K. (1992). Property Tax Auction Sales, Land Economics, 68, 72-82.

Dotzour, M.G., Moorhead, E. \& Winkler, D.T. (1998). The Impact of Auctions on Residential Sales Prices in New Zealand, Journal of Real Estate Research, 16, 57-71.

French, K.R. \& McCormick, R.E. (1984). Sealed Bids, sunk Costs and the Process of Competition, Journal of Business, 57, 417-441.

Gilbert, R.J. \& Klemperer, P.D. (2000). An Equilibrium Theory of Rationing, Rand Journal of Economics, 86, 180-94.

Glower, M., Haurin, D.R. \& Hendershott, P.H. (1998). Selling Time and Selling Price: the Influence of Seller Motivation, Real Estate Economics, 26, 719-740.

Goeree, J.K. \& Offerman, T. (2002). Efficiency in Auctions with Private and Common Values: An Experimental Study, American Economic Review, 92, 625-643.

Goeree, J.K. \& Offerman, T. (2003). Competitive Bidding in Auctions with Private and Common Values, The Economic Journal, 113, 598-613.

Harris, M. \& Raviv, A. (1981). A Theory of Monopoly Pricing with Demand Uncertainty, American Economic Review, 71, 347-365. 
Holt, C. (1979). Uncertainty and the Bidding for Incentive Contracts, American Economic Review, 69, 697-705.

Jeitschko, T.D. (1999). Equilibrium Price Paths in Sequential Auctions with Stochastic Supply, Economic Letters, 64, 67-72.

Jofre-Bonet, M. \& Pesendorfer, M. (2003). Estimation of a Dynamic Auction Game, Econometrica, 71, 1443-1489.

Levin, D., Kagel, J.H. \& Richard, J.F. (1996). Revenue Effects and Information Processing in English Common Value Auctions, American Economic Review, 86, 442-460.

Lusht, K. (1996). A Comparison of Prices Bought by English Auctions and Private Negotiations, Real Estate Economics, 24, 517-530.

McAfee, P. \& McMillan, J. (1987). Auctions with a Stochastic Number of Bidders, Journal of Economic Theory, 43, 1-19.

McAfee, R. P., Quan, D.C. \& Vincent, D.R. (2002). How to Set Minimum Acceptable Bids, with an Application to Real Estate Auctions, Journal of Industrial Economics, 50, 391-416.

McQuinn, K. (2004). A Model of the Irish Housing Sector, Research Technical Paper 1/RT/04, Central Bank \& Financial Services Authority of Ireland.

Mayer, C. (1995). A Model of Negotiated Sales Applied to Real Estate Auctions, Journal of Urban Economics, 38, 1-22.

Mayer, C. (1998). Assessing the Performance of Real Estate Auctions, Real Estate Economics, 26, 41-66.

Milgrom, P. (1986). Auction Theory: Advances in Economic Theory, Truman Bewley (Ed)., Cambridge University Press: Cambridge: MA.

Milgrom, P. (1989). Auctions and Bidding: A Primer, Journal of Economic Perspectives, 3, $3-22$.

Milgrom, P. \& Weber, R. (1982). A Theory of Auctions and Competitive Bidding, Econometrica, 50, 1089-1121.

Milgrom, P. \& Weber, R. (2000). A Theory of Auctions and Competitive Bidding II, in Klemperer, P. (ed). The Economic Theory of Economics, Edward Elgar Publishing: Cheltenham, 179-194.

Nautz, D. \& Wolfstetter, E. (1997). Bid-Shading and Risk Aversion in Multi-Unit Auctions with Many Bidders, Economic Letters, 56, 195-200.

Newell, G., MacFarlane, J., Lusht, K. \& Bulloch, S. (1993). Empirical Analysis of Real Estate Auction versus Private Sale Performance, working paper, University of Western Sydney.

Ong, S.E. (2006). Price Discovery in Real Estate Auctions: The Story of Unsuccessful Attempts, Journal of Real Estate Research, 28, 39-59.

Ong, S.E., Lusht, K. \& Mak, C.Y. (2005). Factors Influencing Auction Outcomes: Bidder Turnout, Auction Houses and Market Conditions, Journal of Real Estate Research, 27, 177191.

Ooi, J.T.L., Sirmans, C.F. \& Turnbull, G.K. (2006). Price Formation under Small Numbers Competition: Evidence from Land Auctions in Singapore, Real Estate Economics, 34, 51-76. 
Pessendorfer, W. \& Swinkels, J.M. (2000). Efficiency and Information Aggregation in Auctions, American Economic Review, 90, 499-525.

Quan, D.C. (2002). Market Mechanism Choice and Real Estate Disposition: Search versus Auction, Real Estate Economics, 30, 365-384.

Roche, M. (2001). The Rise in House Prices in Dublin: Bubble, Fad or just Fundamentals, Economic Modelling, 18, 281-295.

Saidi, R. and Marsden, J. (1992). Number of Bids, Number of Bidders and Bidding Behavior in Outer-continental Shelf Oil Lease Auction Markets, European Journal of Operational Research, 58, 3, 335-343.

Stevenson, S. (2008). Modelling Housing Market Fundamentals: Empirical Evidence of Extreme Market Conditions, Real Estate Economics, 36, 1-29.

Stevenson, S., Young, J. \& Gurdgiev, C. (2010). A Comparison of the Appraisal Process for Auction and Private Treaty Residential Sales, Journal of Housing Economics, 19, 157-166.

Vickrey, W. (1961). Counterspeculation, Auctions and Competitive Seal Tenders, Journal of Finance, 16, 8-37.

Vulcano, G., van Ryzin, G. \& Maglaras, C. (2002). Optimal Dynamic Auctions for Revenue Management, Management Science, 48, 1388-1407.

Wang, R. (1993). Auctions versus Posted-Price Selling, American Economic Review, 83, 838851.

Wilson, R. (1977). A Bidding Model of Perfect Competition, Review of Economic Studies, 44, 511-518.

Zeithammer, R. (2007). Strategic Bid-Shading and Sequential Auctioning with Learning from Past Prices, Management Science, 53, 1510-1519. 


\section{Tables \& Figures}

Table 1: Summary Statistics

\begin{tabular}{|c|c|c|c|c|c|}
\hline & Mean & Median & Minimum & Maximum & Number \\
\hline \multicolumn{6}{|l|}{ Panel A: Overall Sample } \\
\hline Sale Price & $452,033.91$ & 358,000 & 117,100 & $2,750,000$ & 289 \\
\hline Guide Price & $418,542.08$ & 327,500 & 85,000 & $3,200,000$ & 404 \\
\hline Reserve Price & $424,125.00$ & 340,000 & 100,000 & $2,200,000$ & 240 \\
\hline Withdrawn Price & $498,388.24$ & 350,000 & 110,0000 & $3,200,000$ & 85 \\
\hline Number in Attendance & 20.37 & 14 & 0 & 70 & 404 \\
\hline Number of Bids & 12.32 & 8 & 0 & 88 & 404 \\
\hline Number of Bidders & 2.25 & 2 & 0 & 10 & 404 \\
\hline Number of Auctions on Day & 2.34 & 2 & 1 & 7 & 404 \\
\hline Bathrooms & 1.73 & 1.5 & 1 & 5 & 404 \\
\hline Bedrooms & 3.81 & 4 & 1 & 8 & 404 \\
\hline \multicolumn{6}{|l|}{ Panel B: Withdrawn Sample } \\
\hline Sale Price & $428,828.21$ & 327,000 & 134,000 & $1,750,000$ & 77 \\
\hline Guide Price & $485,816.75$ & 390,000 & 120,000 & $3,200,000$ & 191 \\
\hline Reserve Price & $475,674.16$ & 390,000 & 130,000 & $1,300,000$ & 89 \\
\hline Withdrawn Price & $498,388.24$ & 350,000 & 110,0000 & $3,200,000$ & 85 \\
\hline Number in Attendance & 13.60 & 9 & 0 & 60 & 191 \\
\hline Number of Bids & 2.13 & 0 & 0 & 41 & 191 \\
\hline Number of Bidders & 0.79 & 0 & 0 & 5 & 191 \\
\hline Number of Auctions on Day & 2.37 & 2 & 1 & 7 & 191 \\
\hline Time After Auction to Subsequent Sale & 9.88 & 1 & 0 & 56 & 77 \\
\hline Bathrooms & 1.86 & 2 & 1 & 5 & 191 \\
\hline Bedrooms & 3.88 & 4 & 2 & 7 & 191 \\
\hline \multicolumn{6}{|l|}{ Panel C: Counts for Dummy Variables } \\
\hline & \multicolumn{2}{|c|}{ Overall Sample } & \multicolumn{3}{|c|}{ Withdrawn Sample } \\
\hline Apartment & \multicolumn{2}{|c|}{$25(6.19 \%)$} & \multicolumn{2}{|c|}{$13(6.81 \%)$} & \\
\hline Bungalow & \multicolumn{2}{|c|}{$69(17.08 \%)$} & \multicolumn{2}{|c|}{$33(17.28 \%)$} & \\
\hline Detached & \multicolumn{2}{|c|}{$110(27.23 \%)$} & \multicolumn{2}{|c|}{$60(31.41 \%)$} & \\
\hline Semi-Detached & \multicolumn{2}{|c|}{$96(23.76 \%)$} & \multicolumn{2}{|c|}{$36(18.85 \%)$} & \\
\hline Terrace/Mews & \multicolumn{2}{|c|}{$104(25.74 \%)$} & \multicolumn{2}{|c|}{$49(25.65 \%)$} & \\
\hline Central City & \multicolumn{2}{|c|}{$27(6.68 \%)$} & \multicolumn{2}{|c|}{$11(5.76 \%)$} & \\
\hline North City & \multicolumn{2}{|c|}{$45(11.14 \%)$} & \multicolumn{2}{|c|}{$18(9.42 \%)$} & \\
\hline South City & \multicolumn{2}{|c|}{$161(39.85 \%)$} & \multicolumn{2}{|c|}{$72(37.70 \%)$} & \\
\hline South County Dublin & \multicolumn{2}{|c|}{$133(32.92 \%)$} & \multicolumn{2}{|c|}{$68(35.60 \%)$} & \\
\hline Periphery & \multicolumn{2}{|c|}{$38(9.41 \%)$} & \multicolumn{2}{|c|}{$22(11.52 \%)$} & \\
\hline
\end{tabular}

Notes: Table 1 reports summary statistics for some of the key variables. The summary statistics are reported on the basis of both the overall sample and the properties that were withdrawn. 
Table 2: Sale Mechanism Tests

\begin{tabular}{|c|c|c|}
\hline & Guide Prices & Sale Prices \\
\hline & 11.7187 & 11.8826 \\
\hline \multirow[t]{2}{*}{ Constant } & $(77.1991 * * *)$ & $(70.1556 * * *)$ \\
\hline & -0.1097 & 0.0608 \\
\hline \multirow[t]{2}{*}{ Sold at Auction Dummy } & $(-2.2938 * *)$ & $(1.1706)$ \\
\hline & 0.0019 & 0.0515 \\
\hline \multirow[t]{2}{*}{ Sold Prior Dummy } & $(0.0178)$ & $(0.4772)$ \\
\hline & 0.2556 & 0.2279 \\
\hline \multirow[t]{2}{*}{ Bathrooms } & $(3.2663 * * *)$ & $(2.8386 * * *)$ \\
\hline & 0.6124 & 0.5577 \\
\hline \multirow[t]{2}{*}{ Bedrooms } & $(6.3483 * * *)$ & $(5.0659 * * *)$ \\
\hline & 0.0739 & 0.0593 \\
\hline \multirow[t]{2}{*}{ Parking } & $(1.2805)$ & $(0.9190)$ \\
\hline & 0.1420 & 0.1633 \\
\hline \multirow[t]{2}{*}{ Apartment } & $(1.6696 *)$ & $(1.6477)$ \\
\hline & 0.0006 & -0.0407 \\
\hline \multirow[t]{2}{*}{ Terrace/Mews } & $(0.0080)$ & $(-0.5081)$ \\
\hline & -0.0096 & -0.0293 \\
\hline \multirow[t]{2}{*}{ Semi-Detached } & $(-0.1497)$ & $(-0.4341)$ \\
\hline & 0.3232 & 0.2850 \\
\hline \multirow[t]{2}{*}{ Detached } & $(4.1586 * * *)$ & $(3.3569 * * *)$ \\
\hline & 0.0898 & 0.0632 \\
\hline \multirow[t]{2}{*}{ Central Dublin } & $(0.8642)$ & $(0.5986)$ \\
\hline & 0.2019 & 0.2206 \\
\hline \multirow[t]{2}{*}{ South City } & $(2.6927 * * *)$ & $(2.9281 * * *)$ \\
\hline & 0.1860 & 0.1998 \\
\hline \multirow[t]{2}{*}{ South County Dublin } & $\left(2.3586^{* *}\right)$ & $(2.5349 * *)$ \\
\hline & 0.0824 & 0.0471 \\
\hline \multirow[t]{2}{*}{ Periphery } & $(0.9039)$ & $(0.4571)$ \\
\hline & -0.3312 & -0.3108 \\
\hline \multirow[t]{2}{*}{1998} & $(-4.93000 * * *)$ & $\left(-4.0686^{* * *}\right)$ \\
\hline & -0.1786 & -0.1137 \\
\hline \multirow[t]{2}{*}{1999} & $(-2.5326 * *)$ & $(-1.4575)$ \\
\hline & 0.3637 & 0.3623 \\
\hline \multirow[t]{2}{*}{2001} & $(3.6637 * * *)$ & $(3.2602 * * *)$ \\
\hline & 0.4184 & 0.4854 \\
\hline 2002 & $(4.0636 * * *)$ & $(4.2242 * * *)$ \\
\hline $\mathrm{R}^{2}$ adjusted & 0.5780 & 0.5116 \\
\hline Observations & 289 & 289 \\
\hline
\end{tabular}

Notes: Table 2 reports the coefficients estimated from a log hedonic model using Sale and Guide Prices as the dependent variables. * indicates significance at $10 \%, * *$ at $5 \%$ and $* * *$ at $1 \%$. 
Table 3: Probit Models Examining the Probability of Sale of Withdrawn Properties

\begin{tabular}{|c|c|c|c|c|c|c|c|c|c|}
\hline & \multicolumn{3}{|c|}{ Model I } & \multicolumn{3}{|c|}{ Model II } & \multicolumn{3}{|c|}{ Model III } \\
\hline & Coefficient & $\begin{array}{c}\text { Standard } \\
\text { Error }\end{array}$ & T Statistic & Coefficient & $\begin{array}{c}\text { Standard } \\
\text { Error }\end{array}$ & T Statistic & Coefficient & $\begin{array}{c}\text { Standard } \\
\text { Error }\end{array}$ & T Statistic \\
\hline Constant & -0.5082 & 0.7513 & -0.6764 & 1.1998 & 1.2909 & 0.9294 & 3.8125 & 1.8028 & $2.1148 * *$ \\
\hline Bathrooms & -0.2130 & 0.1702 & -1.2519 & -0.1900 & 0.2820 & -0.6736 & -0.0438 & 0.0871 & -0.5036 \\
\hline Bedrooms & -0.0593 & 0.1404 & -0.4222 & -0.3204 & 0.2544 & -1.2595 & -0.0015 & 0.0864 & -0.0169 \\
\hline Parking & -0.0665 & 0.2527 & -0.2632 & -0.9375 & 0.4559 & $-2.0565 * *$ & -0.2393 & 0.1353 & $-1.7688^{*}$ \\
\hline Apartment & 0.0790 & 0.561 & 0.1408 & 0.1118 & 1.3551 & 0.0825 & 0.1133 & 0.2995 & 0.3782 \\
\hline Terrace/Mews & -0.2066 & 0.3866 & -0.5345 & -0.3412 & 0.6539 & -0.5219 & 0.0115 & 0.1802 & 0.0640 \\
\hline Semi-Detached & -0.2597 & 0.4000 & -0.6493 & 0.0108 & 0.6264 & 0.0172 & 0.0552 & 0.1845 & 0.2989 \\
\hline Detached & -0.1464 & 0.3509 & -0.4173 & -0.1424 & 0.6478 & -0.2200 & 0.1201 & 0.1871 & 0.6421 \\
\hline Central Dublin & 0.9068 & 0.5852 & 1.5495 & 1.0040 & 1.1274 & 0.8905 & 0.0507 & 0.3102 & 0.1633 \\
\hline South City & 0.5240 & 0.3978 & 1.3173 & 0.2235 & 0.6283 & 0.3558 & 0.0273 & 0.1818 & 0.1501 \\
\hline South County Dublin & 0.4158 & 0.3952 & 1.0523 & -0.0933 & 0.6679 & -0.1397 & -0.0526 & 0.1921 & -0.2739 \\
\hline Periphery & 0.3193 & 0.5103 & 0.6258 & 0.0235 & 0.9363 & 0.0251 & 0.0568 & 0.2703 & 0.2101 \\
\hline 1998 & 1.5586 & 0.3499 & $4.4539 * * *$ & 2.2090 & 0.7500 & $2.9454 * * *$ & 0.4580 & 0.1815 & $2.5230 * *$ \\
\hline 1999 & 0.9531 & 0.3495 & $2.7267 * * *$ & 0.9884 & 0.7231 & 1.3700 & 0.2410 & 0.1740 & 1.3856 \\
\hline 2001 & 0.7615 & 0.4061 & $1.8753^{*}$ & 0.9020 & 1.0132 & 0.8903 & 0.2032 & 0.2475 & 0.8212 \\
\hline 2002 & -0.7513 & 0.7838 & -0.9585 & 0.0549 & 1.9018 & 0.0289 & 0.1169 & 0.3604 & 0.3243 \\
\hline Auction Attendance & 0.0025 & 0.0083 & 0.3051 & 0.0044 & 0.0160 & 0.2724 & -0.0012 & 0.0041 & -0.3037 \\
\hline Number of Bidders & 0.1654 & 0.2847 & 0.5811 & 0.4309 & 0.3908 & 1.1026 & 0.0274 & 0.1087 & 0.2524 \\
\hline Number of Bids & 0.0049 & 0.0460 & 0.1060 & -0.0282 & 0.0633 & -0.4458 & 0.0018 & 0.0172 & 0.1022 \\
\hline Multiple Auctions & -0.4421 & 0.3052 & -1.4486 & -0.8268 & 0.5760 & -1.4354 & -0.1214 & 0.1681 & -0.7224 \\
\hline No Bids & -0.6345 & 0.3849 & $-1.6485^{*}$ & -1.0280 & 0.5870 & $-1.7513 *$ & -0.2506 & 0.1625 & -1.5422 \\
\hline Order of Auction & 0.2202 & 0.2825 & 0.7795 & 0.4990 & 0.4607 & 1.0832 & -0.0035 & 0.1288 & -0.0272 \\
\hline New Guide-Guide (\%) & 1.3031 & 1.2018 & 1.0843 & - & - & - & - & - & - \\
\hline New Guide-Reserve (\%) & - & - & - & 6.3389 & 3.1271 & $2.0271 * *$ & - & - & - \\
\hline Reserve Price & - & - & - & - & - & - & -0.2573 & 0.1523 & $-1.6895^{*}$ \\
\hline McFadden $\mathrm{R}^{2}$ & 0.2500 & & & 0.3664 & & & 0.3938 & & \\
\hline Observations & 190 & & & 88 & & & 89 & & \\
\hline
\end{tabular}

Notes: Three alternative specifications of a Binary Probit model are estimated on those properties that were withdrawn at auction. The dependent variable in a binary variable which takes the value of unity if the property sold following the auction and zero if it remained unsold. * indicates significance at $10 \%$, ** at $5 \%$ and $* * *$ at $1 \%$. 
Table 4: Sale Premiums on Withdrawn Properties

\begin{tabular}{lccc}
\hline & Sale-Open Bid (\%) & Sale-Guide (\%) & Sale-Reserve $(\%)$ \\
\hline \multirow{2}{*}{ Constant } & 0.2157 & -0.0855 & -0.0221 \\
& $(0.2146)$ & $(0.1150)$ & $(0.0577)$ \\
Auction Attendance & 0.0002 & 0.0022 & 0.0007 \\
& $(0.0025)$ & $(0.0021)$ & $(0.0006)$ \\
Number of Bidders & 0.0881 & 0.0726 & -0.0138 \\
& $(0.0375)^{* *}$ & $(0.0380)^{*}$ & $(0.0140)$ \\
Number of Bids & -0.0018 & -0.0012 & 0.0047 \\
Multiple Auctions & $(0.0048)$ & $(0.0051)$ & $(0.0022)^{* *}$ \\
& 0.0055 & -0.0741 & -0.0120 \\
No Bids & $(0.0550)$ & $(0.0291)^{* *}$ & $(0.0268)$ \\
& & 0.1103 & 0.0001 \\
Previous Auction Sold & - & $(0.0431)^{* *}$ & $(0.0188)$ \\
& $(0.0839)$ & -0.0248 & -0.0264 \\
Order of Auction & -0.0654 & $(0.0599)$ & $(0.0312)$ \\
& $(0.0782)$ & 0.0663 & 0.0138 \\
$\mathrm{R}^{2}$ adjusted & 0.0879 & $(0.0454)$ & $(0.0263)$ \\
Observations & 48 & 0.2119 & 0.3855 \\
\hline
\end{tabular}

Notes: Three alternative OLS models are estimated with the percentage change of the sale price over the opening bid, guide and reserve price. The sample is constrained to just consider those properties that were withdrawn at auction. The full results including the property specific variables are available from the authors. The figures in parentheses are standard errors. $*$ indicates significance at $10 \%, * *$ at $5 \%$ and $* * *$ at $1 \%$. 


\section{Endnotes:}

${ }^{1}$ Ireland has a very high owner-occupancy rate, even in 2011 following the recent crash it stood at approximately $70 \%$. This means that valuations are determined by the comparable sales method and do not relate to the rental market.

${ }^{2}$ The current market conditions in Ireland are obviously different from those prevailing during the sample. More recently auctions have been used more frequently in the context of distressed/foreclosed sales with also a larger number of properties offered at one auction.

${ }^{3}$ One of the anonymous referees notes that due to these high barriers to entry and an increased opportunity cost there may be a selection bias from the perspective of the bidders. This may arise in that potential bidders with higher opportunity costs may be attracted towards the premium end of the market. This is hard to explicitly consider without the availability of a comparably detailed private treaty sample. It should be emphasised though that as Stevenson et al. (2010) illustrate, during this period the majority of highly valued properties sold through auction. Furthermore, in addition to the requirement of an immediate non-refundable deposit, extremely high stamp duty rates at the premium end of the market were liable during this period (see Berry et al., 2001).

${ }^{4}$ See also papers such as Harris \& Raviv (1981), McAfee \& McMillan (1988) and Campbell \& Levin (2006).

${ }^{5}$ The role of the number of bidders in obtaining higher prices at auction is shown in theoretical papers such as Vickery (1961), Holt (1979), Harris \& Raviv (1981) and McAfee \& McMillan (1987).

${ }^{6}$ Pesendorfer $\&$ Swinkels (2000) note that a large number of bidders can lead to a resumption of efficiency, even in the case of a two-signal auction.

${ }^{7}$ On a more general note Chow et al. (2010) also support the previously cited work relating to the importance of market conditions and that auctions are more likely to outperform during periods of strong house price appreciation.

${ }^{8}$ The authors would like to thank one of the anonymous referees for highlighting the issue of bid-shading. For broader discussions concerning bid-shading see papers such as Jeitschko (1999), Jofre-Bonet \& Pesendorfer (2003), Milgorm \& Weber (2000), Nautz \& Wolfstetter (1997), Vulcano et al. (2002) and Zeithammer (2007).

${ }^{9}$ The arguments laid out by Quan (2002) can also be assessed in this context. Quan (2002) illustrates that bidders with higher search costs will tend to participate in auctions. Properties at the premium end of the market would fit this description. Quan (2002) also provides evidence that the price obtained should be enhanced in an auction context.

${ }^{10}$ In markets such as the United States and also Singapore where a large proportion of auctions involve distressed sales the situation may be quite different. As Ong et al. (2005) note the sellers of distressed properties may be more willing to sell quickly and at a discounted price in order to recoup some of their investment. In contrast willing sellers will be less willing to either sell quickly or at a discount. If an auction market, such as Ireland, is dominated by willing sellers then this does make a distinct difference based on the nature of the sellers concerned and a possible reduced likelihood of an auction discount being observed, particularly during strong housing market conditions. 
${ }^{11}$ It should be noted that the Milgrom \& Weber (1982) model that shows the preference over sealed bids is illustrated in the case of 'irrevocable exit', whereby bidders who withdraw from the auction cannot subsequently re-enter. Sealed bid auctions will maximize revenue in the case of independent bids and risk-averse bidders.

${ }^{12}$ Under an assumption of independent private values this therefore reverts to the Vickery (1961) structure whereby the good is purchased by the bidder who has the highest private value.

${ }^{13}$ Part of the conditions agreed to when obtaining the data was that the auction house remains anonymous. Furthermore, the sensitive nature of the data meant that no data after 2002 was released.

${ }^{14}$ See studies such as Berry et al. (2001), D'Agostino et al. (2008, McQuinn (2004), Roche (2001) and Stevenson (2008) for more general discussions concerning the dynamics of the Irish housing market during this period.

${ }^{15}$ The proportion of the sample that is withdrawn at auction is quite high at $47 \%$; it is also higher than that reported by Stevenson et al. (2010) in their analysis of the Irish auction market. This may simply be due to the auction house concerned adopting a more rigorous policy in this regard. As noted previously in the paper the convention in Ireland is that the highest bidder in the auction, even though unsuccessful has the right of first negotiation. The fact that the majority of the properties withdrawn sold very quickly would imply that in many cases the property was sold to someone present at the auction. It is therefore possible that the auction house withdrew properties with this knowledge feeling that subsequent private negotiations may result in a more favourable outcome.

${ }^{16}$ It should be noted that the number of bids and bidders is specific to the individual auction and is not aggregated across all auctions held that day. This likewise is the case in the scenario of no bids.

${ }^{17}$ See Stevenson et al. (2010).

${ }^{18}$ We would like to thank one of the anonymous referees for their observations on this point.

${ }^{19}$ An earlier version of this paper took the more conventional route and excluded the 1998 dummy from the models. However, given the strong upward movement in the market this resulted in all of the included time dummies being positive and significant. This did lead to some confusion when the earlier version of the paper was presented. The choice of excluded dummy is arbitrary and does not impact on the coefficients for other variables, therefore to avoid potential mis-understandings we re-ran the analysis with 2000 excluded. The original results are available from the authors on request.

${ }^{20} \mathrm{We}$ did also consider the use of a measure of time-on-market post auction. However, as already noted, the fact that most properties sold very quickly following their withdrawal meant that meaningful results were not obtained when such a measure was included in the analysis.

${ }^{21}$ For the sake of brevity Table 4 only reports the coefficients for those variables directly related to the auction process. However, the models did include all of the property specific control variables incorporated into the previous models. The full results are available from the authors on request. As would be expected given the nature of the tests, the control variables were largely insignificant. Indeed, only one variable was found to be significant at 
conventional. This case was for the Central City location dummy in the Sale-Reserve specification when it was noted as being significantly negative. 